University of South Carolina

Scholar Commons

$5-1991$

\title{
Sponsoring the Next Generation: Parental Willingness to Pay for Higher Education
}

\author{
Lala C. Steelman \\ University of South Carolina - Columbia, steelman@sc.edu \\ Brian Powell
}

Follow this and additional works at: https://scholarcommons.sc.edu/socy_facpub

Part of the Sociology Commons

\author{
Publication Info \\ American Journal of Sociology, Volume 96, Issue 6, 1991, pages 1505-1521.
}

This Article is brought to you by the Sociology, Department of at Scholar Commons. It has been accepted for inclusion in Faculty Publications by an authorized administrator of Scholar Commons. For more information, please contact digres@mailbox.sc.edu. 


\section{| CHICAgo JOURNALS}

Sponsoring the Next Generation: Parental Willingness to Pay for Higher Education Author(s): Lala Carr Steelman and Brian Powell

Source: The American Journal of Sociology, Vol. 96, No. 6 (May, 1991), pp. 1505-1529

Published by: The University of Chicago Press

Stable URL: http://www.jstor.org/stable/2781909

Accessed: $0 7 \longdiv { / 1 0 / 2 0 1 0 ~ 1 2 : 4 9 }$

Your use of the JSTOR archive indicates your acceptance of JSTOR's Terms and Conditions of Use, available at http://www.jstor.org/page/info/about/policies/terms.jsp. JSTOR's Terms and Conditions of Use provides, in part, that unless you have obtained prior permission, you may not download an entire issue of a journal or multiple copies of articles, and you may use content in the JSTOR archive only for your personal, non-commercial use.

Please contact the publisher regarding any further use of this work. Publisher contact information may be obtained at http://www.jstor.org/action/showPublisher?publisherCode=ucpress.

Each copy of any part of a JSTOR transmission must contain the same copyright notice that appears on the screen or printed page of such transmission.

JSTOR is a not-for-profit service that helps scholars, researchers, and students discover, use, and build upon a wide range of content in a trusted digital archive. We use information technology and tools to increase productivity and facilitate new forms of scholarship. For more information about JSTOR, please contact support@jstor.org.

The University of Chicago Press is collaborating with JSTOR to digitize, preserve and extend access to The American Journal of Sociology. 


\title{
Sponsoring the Next Generation: Parental Willingness to Pay for Higher Education ${ }^{1}$
}

\author{
Lala Carr Steelman \\ University of South Carolina \\ Brian Powell \\ Indiana University
}

\begin{abstract}
Although sociologists and economists have been widely concerned with parental investment in children, that investment has rarely been examined directly. The Parent Survey of the High School and Beyond data set provides material for examining the traits of parents and children that shape parental payment for higher education. Parents' reported willingness and ability to pay, along with savings for children's future education, are shaped first by total income and the number of children who must share that income. Moreover, parental investment in higher education is increased when the parents themselves received parental financial support, which suggests continuity over generations. Gender of parent and child, academic achievement of child, marital status, education, and educational aspirations have more mixed and weaker effects. These findings cause a rethinking of the mechanisms of intergenerational influence as seen by status-attainment, human capital, and resource-dilution perspectives.
\end{abstract}

The extent to which parents invest in their children has long been recognized as integral to status attainment. Nevertheless, that investment is rarely examined directly. The dearth of evidence on parental investment in higher education is especially discouraging. With the marked increase in the percentage of youths entering college over the past few decades, college graduation increasingly demarcates the middle class from the working class (Vanneman and Pampel 1977). The role parental investment plays in facilitating college attendance and therefore in sustaining

\footnotetext{
${ }^{1}$ Preparation of this paper was supported by National Science Foundation grant SES-8508301 to Steelman and a Spencer Fellowship to Powell. We thank Doug Downey, Carl Ek, and Ann Smith for their assistance and the anonymous reviewers for their suggestions. The authors' contributions are equal. Requests for reprints should be sent to Brian Powell, Department of Sociology, Indiana University, Bloomington, Indiana 47405 .
}

(C) 1991 by The University of Chicago. All rights reserved. 0002-9602/91/9606-0007\$01.50 
class distinctions is considerable (Steelman and Powell 1989). Although the family has relinquished many of its traditional functions, financing a child's higher education is one parental obligation that has not been abdicated. Indeed, the American system of higher education is predicated on the assumption that parents, even those in the lowest income brackets, should shoulder the lion's share of college expenses (Carnegie Commission on Higher Education 1973; Olson and Rosenfeld 1984; Miller 1985).

Despite cultural expectations, all parents may not subscribe to the view that they should subsidize higher education. Instead, financial responsibility may be assigned to two alternative sources: the student or the government. Moreover, how parents act may not necessarily correspond to their philosophy of the parental role. In principle, parents may acknowledge a responsibility as theirs but simultaneously visualize it as something beyond their means, or parents may set limits on the economic sacrifices they are willing to make for children. Whatever factors lessen parents' optimism that they can handle college costs may conversely raise the extent to which they see their children as independently capable of handling collegiate expenses.

In this article, we examine parental investment in higher education in terms of (1) whether parents place primary responsibility for financing a college education on themselves, their children, or the government; (2) parental accounts of their ability and willingness to assist their children and of their children's ability to handle college expenses independently; and (3) how much parents have saved for their child's education. We contend that parental investment varies as a function of parental traits, characteristics of the child, and the number of children in the family.

\section{SOURCES OF VARIATION IN PARENTAL FINANCIAL ASSISTANCE}

In hypothesizing which factors should be related to parental investment, we borrow from the human capital tradition (Becker 1964, 1967, 1981; Becker and Tomes 1976; Taubman and Behrman 1986), the statusattainment model (Blau and Duncan 1967; Sewell and Hauser 1976), and the resource-dilution hypothesis (Anastasi 1956; Blake 1989). Advanced by economists, human capital theory investigates the investments, sacrifices, bequests, and time inputs that parents make on behalf of their children. Unlike the conceptualization of the child as an economic liability that does nothing but consume, the human capital model sees the child as an investment. According to this perspective, parents, who operate in a rational mode, calculate expected pecuniary and nonpecuniary returns on investments in children. Resources are then vested in ways that maximize the probability of future payoffs. How many resources parents can dole out to children is contingent on familial assets and the number of 
claimants in the family entitled to them. Parental investment is further affected by the degree to which any child exhibits promise, or what human capitalists call "genetic endowments."

Although recent studies have attempted to correct the "cultural myopia" that characterizes human capital research by examining crosscultural heterogeneity in parental investment in children (Brinton 1988, p. 305), we contend that the study of parental investment in the United States is far from complete. College funding is a case in point. Since human capital theorists have worked hard to specify the returns on higher education (Blaug 1976), it is puzzling that the factors affecting parental financial aid for college remain virtually untested. Only by directly examining parental attitudes and behavior toward their responsibility in assisting children can researchers go to the heart of the human capital argument.

The status-attainment model may well represent the most commonly used paradigm in the sociological literature. It accounts for socioeconomic success as a function of an individual's family background, aspirations, level of ability, and other intervening social-psychological factors (Blau and Duncan 1967; Featherman and Hauser 1978). While this model has been replicated extensively with particular attention paid to parental aspirations and encouragement, the explicit link between family background and parental financial support has been overlooked.

The commonality between the status-attainment model and the human capital perspective is readily apparent: both emphasize socioeconomic background, the number of children in the family, and characteristics of the child. The difference lies in the interpretation of the status-attainment process. The "Wisconsin school" stresses social-psychological factors, such as parents' educational aspirations for their children, as intervening factors between socioeconomic background and success in contrast to the rational calculation of returns on investments emphasized by human capitalists. Although our research cannot arbitrate between these two major theoretical perspectives, we can, at the very least, test some implications of these interpretations as they pertain to parental responsibility.

The last perspective guiding this research is the resource-dilution hypothesis that focuses on the nexus between sibship size and resource distribution (Blake 1989; Anastasi 1956). Although sibship size is acknowledged in sociological research as a predictor of various status outcomes, it is rarely brought to the forefront. This is regrettable because of the consistently found detrimental effect of sibship on educational output. The resource-dilution hypothesis, in contrast, highlights the role of sibship size. According to this perspective, it is not just the absolute level of resources a family commands that is important, but also the number of members among whom these resources are to be divided. The 
more children in the family, the fewer the resources-whether intellectual, social/interactional, or economic - that can accrue to any given child. In turn, educational advancement is increasingly put in jeopardy as families expand in size.

Despite its intuitive appeal, this hypothesis is routinely posed in an ad hoc fashion as opposed to being tested directly. This hypothesis can also be criticized for not outlining the relative influences of various kinds of resources on children. The limited research gauging the effect of family size on parental allocation of resources has centered almost exclusively on social/interactional inputs such as the time spent with children (Liebowitz 1974, 1977). Economic resources have been neglected, perhaps because research in the area typically assesses how sibship size molds the initiating of ability in early childhood. Although social/interactional resources may be pivotal in childhood and early adolescence, the primacy of economic resources may surface in late adolescence when decisions about college are reached.

The human capital, status-attainment, and resource-dilution perspectives guide us in identifying three sets of variables that may be linked to parental investment: characteristics of the parent, traits of the child, and structure of the sibship.

\section{Characteristics of the Parent}

Parents in higher income brackets should more freely endorse and take responsibility for college support than their less financially secure counterparts. The reasoning here is simple: individuals with resources can accept financial responsibility without considerable risk. This expectation is consonant with the status-attainment literature that documents a strong link between parental income and educational attainment. It also squares with the human capital argument that investments in children are based on a rational calculation of potential financial returns (i.e., increased earnings of child resulting from increased education) against college costs incurred. Parents with less at stake economically will more readily bestow resources for higher education than those who potentially face financial difficulties.

According to status-attainment research, individual success is partly contingent on parental SES and aspirations. Parents with more education may place a higher premium on parental assistance than their less well educated peers. As parental aspirations have been shown to be directly linked to college enrollment and eventual educational attainment, we posit that the stronger the parental desire for a child's educational advancement, the greater the parental acceptance and assumption of responsibility. 
Marital status of the parent also may color his or her views and behaviors. Unmarried parents may exhibit and endorse less financial responsibility for their children's education. A single-parent household will have financial constraints not typically encountered by a two-parent household, even when family income is held constant. Change in marital status, whatever the cause (death, divorce), entails financial losses not captured entirely by income. When we use human capital reasoning, we find that the sacrifice to support a college education may be viewed as less tenable in a single-parent than in a two-parent household.

We also include two parental characteristics that are not as clearly derivable from the human capital, status-attainment, or resource-dilution models: sex of the parent and whether parents received financial support for their education from their parents.

Sex of the parent may alter attitudes toward parental responsibility. Human capital theory suggests that mothers should be more inclined to invest in children because women, on the average, have a longer life expectancy than men and therefore have more to gain in the long run by sacrificing for their children's education. Cultural-normative explanations produce competing predictions. If mothers have a unique and closer bond to their children than do fathers, women may be more willing than men to make considerable financial sacrifices. Conversely, if females have greater confidence in the government, they may be more inclined than males to look to it for financial assistance. Norms emphasizing independence among males may manifest themselves in one or two polar directions. Fathers may believe that they are financially capable to cover college costs without outside assistance or that children can and should handle college expenses on their own.

Among parents who pursued higher education themselves, their own experience in educational funding may affect willingness to sponsor their children. Although this variable could be seen as a logical extension of the status-attainment model, it may also be couched in culturalnormative terms. Parents who have been aided by their parents may feel duty bound to provide the same type of assistance they have received. Instead of conventionally predicting a child's life chances as dependent only on the more immediate nuclear family situation, we predict a "transmission" effect that cuts across generations in which parents support their children in a way similar to the way their own parents treated them.

\section{Traits of the Child}

Parental responsibility may additionally be influenced by the academic talents and sex of the child. Status-attainment research indicates that academic performance presumably influences educational aspirations of 
parents and youths and, in turn, the likelihood of college attendance. If we extend this logic, we find that parental propensity to invest in children's college education should be based in part on academic achievement. The effect of achievement may occur indirectly via parental aspirations or may have a direct effect, net of aspirations. The human capital perspective uses academic achievement to gauge "endowments." It contends that parents more readily make monetary sacrifices if their children demonstrate academic prowess because that enhances the odds of financial dividends on college investments.

The projected effects of the youth's sex are not altogether clear. On the one hand, parents may hold sons more accountable than daughters for college expenses. Parents may believe that sons should be more independent than daughters or that sons can be more independent because it is easier for them to get jobs to pay for college. On the other hand, according to human capital rationale, if the expected pecuniary returns on education are lower for females than males, then parents may be less disposed to subsidize their daughter's than their son's education.

Cross-cultural studies chronicle parental investments along gender lines. Brinton (1988) found that Japanese parents were more likely to aspire to a university education for their sons than for daughters. Although she did not explicitly test for sex differences in financial investments in education, she found that nearly all ronin students, that is, students who stay out of a school for a year to study for the comprehensive university entrance examinations, are male. That ronin students are typically subsidized by their parents implies a greater willingness for parents to invest more heavily in the educational training of sons. Brinton traces this pattern partly to the wide gender gap in earnings and the deeply embedded norm that sons will provide for aging parents. Greenhalgh's (1985) study of post-World War II Taiwan revealed a similar son preference, with parents investing minimal resources in their daughters and, in turn, recycling daughters' wages to subsidize the educational attainment of sons. She attributed this form of parental favoritism to sons' lifelong contractual obligation to their parents as opposed to daughters' shifting their allegiance to their husbands. The large gender gap in earnings potential in the United States, although more modest than in Japan, endures. However, other factors that motivate Asian parents to favor sons, such as sex differences in filial obligations, may not be operative in the United States. Whether U.S. parental investment along gender lines parallels the Asian experience remains to be seen.

\section{Sibship Structure}

Finally, the structure of the sibship may elicit differential response from parents. We consider two structural parameters of the sibship: size and 
ordinal position. As size increases, the amount of resources for each family member declines and, accordingly, parents should take less responsibility for college expenditures. This prediction fits into the rubric of the status-attainment and human capital orientations and more explicitly corresponds with the resource-dilution hypothesis.

An examination of the effect of being an early born (i.e., having few or no older siblings and more younger siblings) versus a later born (i.e., having more older siblings than younger siblings) may prove useful. If parents hold greater aspirations or affective preferences for elder borns, parental responsibility for earlier born children may be heightened. Moreover, according to human capital theorists, parents may invest more in earlier born than in later born children because expected dividends should materialize sooner. Indeed, Greenhalgh (1985) noted not only a preference for sons in Taiwan but also parental favoritism to the firstborn. Alternatively, but also in consistency with the human capital argument, later born children may reach college age at a more opportune time in the family life cycle with respect to the availability of parental financial resources.

\section{DATA AND METHODS}

\section{Data}

We use the Parent Survey of the High School and Beyond data set to investigate the effects of parental, student, and sibship characteristics on parental responsibility in funding postsecondary education. An underutilized, lesser known part of the High School and Beyond study, the Parent Survey was collected by NORC under the auspices of the National Center for Educational Statistics (for examples of the use of other sections of High School and Beyond, see Heyns and Hilton [1982]; Lee and Byrk 1988). The Parent Survey is the only data set we located that provides adequate information on family background and asks questions about parents' financial responsibility to their college-age children.

The first wave of High School and Beyond was administered to almost 60,000 high school seniors and sophomores in early 1980. A sample of these students' parents (3,600 parents of sophomores and 3,600 parents of seniors) was drawn. In the fall of 1980 , these parents were surveyed via mail with a follow-up interview for nonrespondents, which together resulted in a $91 \%$ completion rate. We analyze only the parents of seniors because several key variables (e.g., parental willingness to go into debt) were not asked the sophomores' parents and because the issue of college funding should be of greater immediacy to the parents of seniors. Exclusion of missing values and the limitation of the sample to biological or 
adoptive parents (excluding stepparents, guardians, grandparents, and others), decreases the number of cases from 3,197 to $2,327 . .^{2}$ Although our discussion focuses on these parents, results of supplementary analyses, in which we restrict our sample to parents of children attending college, are also displayed in the tables below. ${ }^{3}$

\section{Operational Definitions}

Table 1 presents brief descriptions, weighted means, and standard deviations of the endogenous and exogenous variables. We focus on three dimensions of parental responsibility. The first asks parents where they place "the MAIN responsibility for the cost of education beyond high school." Parental options include the student, the parents, and the state or federal government. This measure represents a general view of financial responsibility because it is not specifically geared to the family or child in question.

The second cluster of questions centers around parental judgments of their specific financial situation. We use four items: whether parents agree that "we can pay for our son's/daughter's further education without getting outside finances"; whether parents "see any way of getting enough money to allow my son/daughter to get more education"; whether "the family is not willing to go into debt for schooling"; and whether their "son/daughter will be able to earn all the money he/she will need for schooling beyond high school." The dichotomous responses were recoded so that greater acceptance of parental obligations was coded as 1 .

The third class of questions taps specific parental behavior as measured by how much parents report having saved for their child's education. This variable is based on two questions: one asks, "Did you or your spouse do anything specific in order to have some money for this child's

${ }^{2}$ The bulk of the missing cases comes from two sources: our restriction to biological parents (a reduction of 178 cases) and the large number of parents who responded "don't know" to the question, "Who should have the MAIN responsibility for the cost of education beyond high school?" (an additional loss of 470 cases). To check for the consequences of the missing values, we also conducted pairwise and mean substitution procedures, when applicable. The direction and magnitude of the patterns presented in this paper, which are based on listwise procedures, are consistent with the alternative procedures.

${ }^{3}$ We tried three alternative sample restrictions: $(a)$ parents who wanted their children to acquire some form of postsecondary education, who made up $95 \%$ of all parents; (b) parents who wanted their child to acquire a college degree; and $(c)$ parents whose children wanted to go beyond high school. All three restrictions yield results analogous to those reported here. 
education after high school?" the other asks, "About how much money did you set aside for your son's/daughter's future educational needs?" (measured in six broad categories and scaled in dollars at the midpoints of the categories).

The independent variables in our analyses include characteristics of the parent, the student, and the sibship. Parental factors are education (coded from "less than high school" to "postbaccalaureate degree"), ${ }^{4}$ family income (in thousands of dollars logged),${ }^{5}$ sex,${ }^{6}$ marital status, ${ }^{7}$ and the educational level that the parents aspire to for their child. ${ }^{8}$ In analyses limited to parents who attended college, we also test for the effects of whether their parents had financially assisted their education. Student traits are sex and academic ability, the latter measured by whether the

\footnotetext{
${ }^{4}$ Because we are interested in the effects of marital status and because unmarried parents were not questioned about the other parent's education, we opted to include the education of the surveyed parents only. In supplementary analyses including the education information of both parents, the education of the person not interviewed had a weaker effect and produced little improvement in the fit of the models. Moreover, the magnitude of the effects of the remaining exogenous variables was unaltered.

${ }^{5}$ Parental income was estimated by the sum of "wages, salary, commissions, or tips from all jobs" and income received "from working on his/her own business or farm" from both parents. Alternative estimates of parental income (both logged and nonlogged) yield parallel conclusions.
}

${ }^{6}$ Although the original intent of the Parent Survey was to reach mothers rather than fathers, approximately $35 \%$ of the parents interviewed were fathers. Our figure is slightly higher, which results primarily from our exclusion of stepparents, grandparents, and guardians and in part from missing values (e.g., women were less likely to offer information on financial matters).

${ }^{7}$ We have analyzed several interactions, including the interaction between marital status and sex. The inclusion of this interaction does not yield a significant improvement in any of our models, suggesting that the effects of marital status and sex are essentially additive.

${ }^{8}$ The choice of parental aspirations creates a timing problem in that parents were surveyed in the fall of 1980 , i.e., after their children should have graduated from high school. We caution the reader that aspirations may have been conditioned by whether their children graduated from high school or attended college. However, we performed several supplementary analyses. First, we excluded parental aspirations from the model. The variables we are most interested in (income, sibship structure, and financial support received by parents) remain significant. Second, we examined the effects of youths' aspirations, both as estimated by parents and as reported by students. Although each measure is remarkably similar, we favor the use of parental aspirations because it is most compatible with the theoretical justification (especially human capital theory) of this research. Third, because it can be viewed as an intervening factor, parental aspiration was regressed on the other variables. We find strong positive effects of test scores, tracking, parental education, and family income and negative effects of being single and the child's being female. Thus, some of the effects of these variables may be indirectly channeled to the endogenous variables via educational aspirations. 


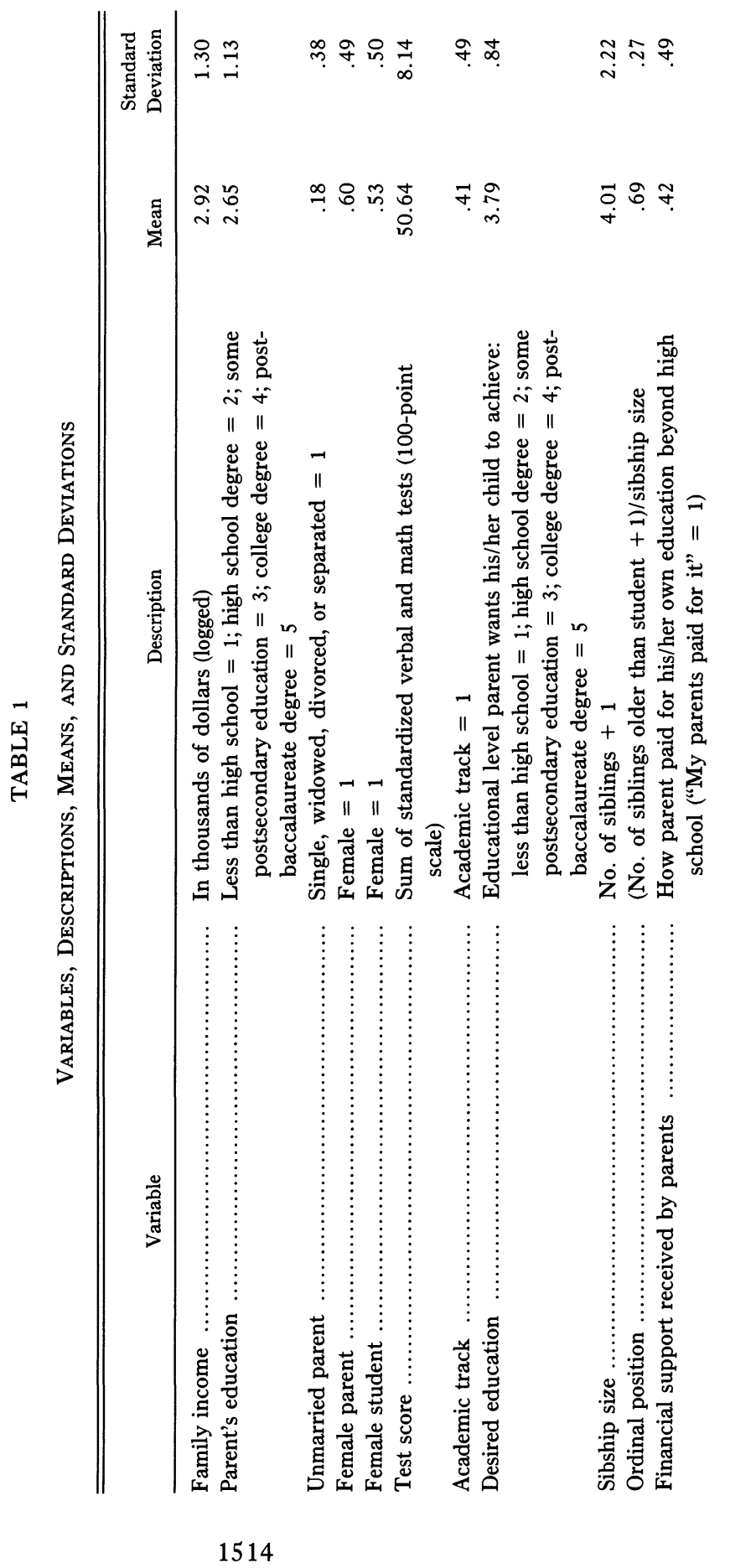




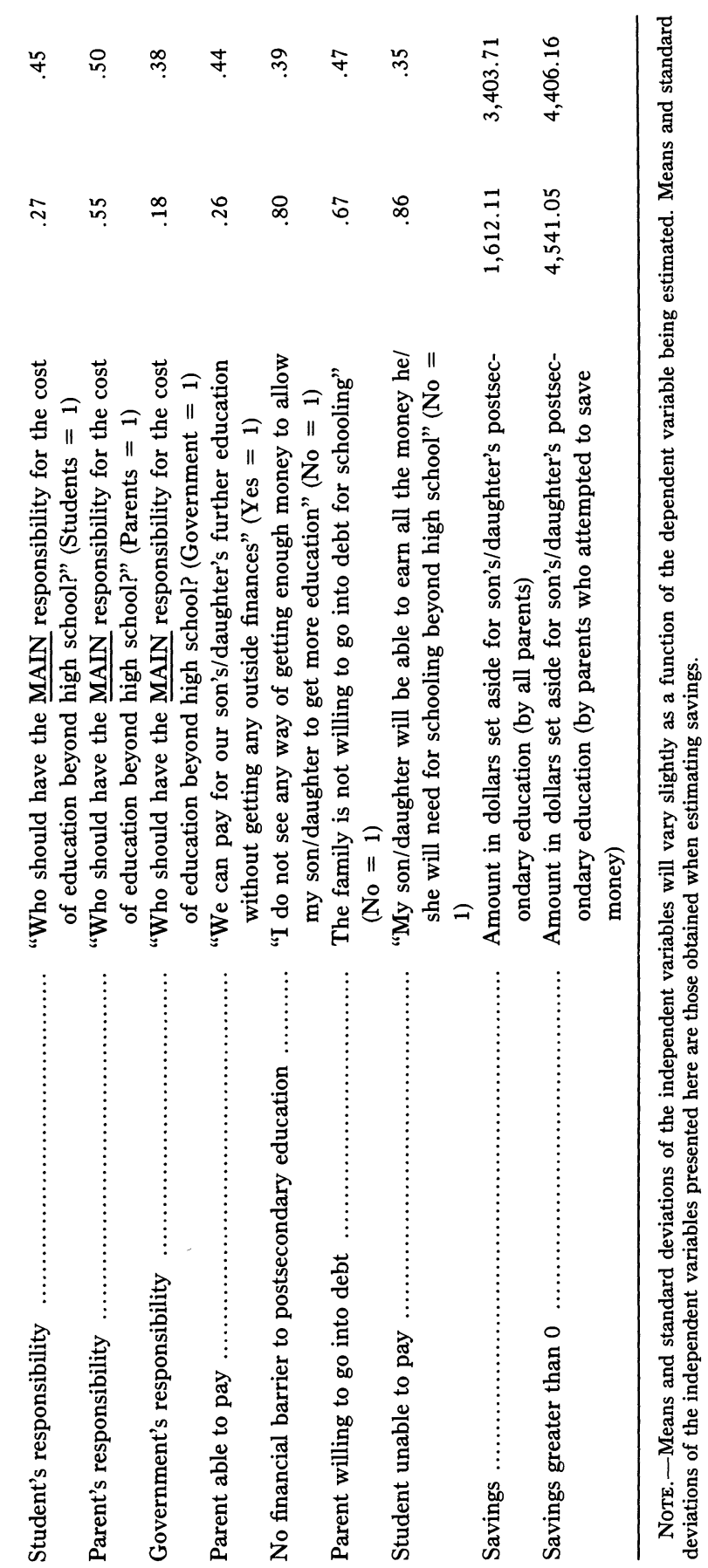


student was placed in an academic track in high school ${ }^{9}$ and by performance on a standardized test constructed by the Educational Testing Service. ${ }^{10}$ We use the mean of the five verbal and math sections of the exam (standardized to a mean of approximately 50). Student traits are used in all models except those predicting general responsibility. We also examine the effect of sibship size (number of children) ${ }^{11}$ and ordinal position, which, to compensate for varying sibship sizes, is divided by sibship size. ${ }^{12}$

\section{RESULTS}

We first consider what factors cause parents to conclude that they, their children, or the government should bear the primary responsibility for funding a college education. With responses trichotomized among parents', student's and government's responsibility, we use a multinomial logit analysis with two sets of logistic parameters - first comparing student responsibility and then that of the government with parental responsibility (see Fienberg 1980; Manski 1980; Maddala 1983).

The most notable feature of the parameter estimates is the effect of

${ }^{9}$ We also tested whether attendance in a private secondary school (first, Catholic schools, and then, all private schools) increased parental responsibility. It could be posited that parents who already provided financial support for their children to attend a private school should be predisposed to continue this support in college. We find no such effect.

${ }^{10}$ In additional analyses using parent-reported grades in lieu of test scores, grades had even less effect than test scores. The use of grades has one advantage-parents may or may not be aware of test scores, whereas student grades are estimated by the parents. We, however, opt for test scores because they are more reliable, normally distributed, and not school-specific.

${ }^{11}$ The Parent Survey of High School and Beyond reports a few cases of unlikely family sizes (i.e., sibships exceeding 12) and a large average sibship size of approximately 4 . As recommended by one reviewer, we have "trimmed" the large sibship sizes by recoding values exceeding 12 as 12 . The effects of sibship size remain essentially the same whether or not these values are trimmed. Although the large sibship size appears inconsistent with the contemporary trend toward smaller families, one should bear in mind that we are using average sibship size per child, not per family unit. Indeed, Preston (1976) illustrates that the mean number of children that had been born to woment who were past their childbearing years in 1940 was 2.6; in contrast, the average sibship size of their children was 5.2.

${ }^{12}$ In calculating ordinal position, we use total number of children as the denominator, in contrast to the "trimmed" number of children. Alternative measures of sibling configuration considered are the number of older siblings vs. the number of younger siblings, the ratio of older to younger siblings, the number of older siblings minus younger siblings, income per sibling, and income per younger sibling. We also included a dummy variable for only borns, because only borns are in the unique position of being a last born and a firstborn simultaneously. These measures yield findings consistent with those reported here. 
sibship size, the magnitude of which exceeds that of any other variable introduced in the equations. As sibship sizes increase, parents' responsibility is increasingly deflected onto students. To illustrate, in estimates in the equation where all other variables are set at the mean, parents with only one child are nearly four times more likely (.65 to .17) to believe that parents rather than children should be accountable for funding education. In contrast, parents with nine children are slightly less likely (.38 to .44) to place responsibility on the parent than on the child.

Despite the somewhat mixed pattern of findings, the overall relationships seem clear. As parental resources increase, so, too, do attributions of parental responsibility. Parents with more education, greater educational aspirations, and fewer children are more likely to believe that children should be relieved of financial responsibility by their parents (table 2, col. 1). Although no subgroup sees government as more responsible than parents for funding college, those who are single and with less income and education are more likely than their married and advantaged counterparts to assign responsibility to the government (table 2, col. 2).

Four items concerned with the financing of a specific child's education increase our understanding of parental investment (table 3). As expected, parental resources are very important. Parents more likely see themselves as capable of paying "for our son's/daughter's future education without getting any outside finances" (table 3, col. 1) when they have more income, have fewer children overall and fewer children younger than the child in question, are currently married, are male, and possess more education. To provide some idea of the magnitudes involved, the logistic regression coefficients imply that the odds of being able to pay are decreased by $57 \%$ if the parent is unmarried, by $21 \%$ if the parent is female, and by $14 \%$ for each additional child. In short, these are sizable effects. It is only these resource-related characteristics that matter-other attitudinal characteristics and characteristics of the child are unimportant.

Similarly, parental prognostications as to whether they "see any way of getting enough money to allow my son/daughter to get more education" are highly related to family resources (table 3, col. 2). Parents with more education, greater income, fewer children, and fewer children younger than the child in question express more optimism. The only non-resource-related item of note is test scores-parents of high-scoring children are less likely to perceive financial obstacles. This finding, although consistent with human capital theory, may alternatively reflect that parents see their academically talented children as being more able to secure loans and scholarships, thus increasing parental ability to pay the remaining educational expenditures.

It may be unsurprising that the presence of family resources increases perceived ability to pay or perceived absence of financial barriers to 


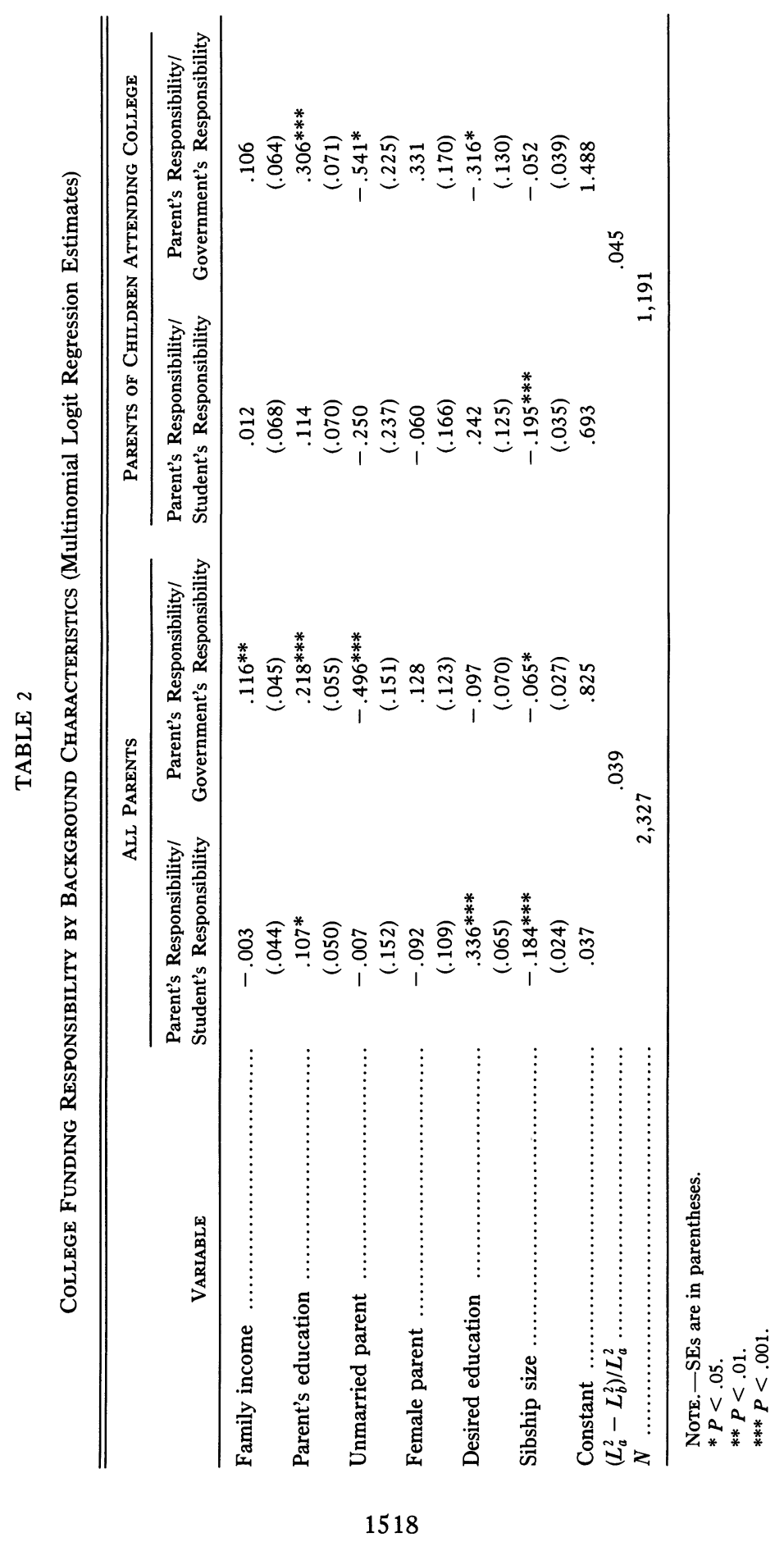




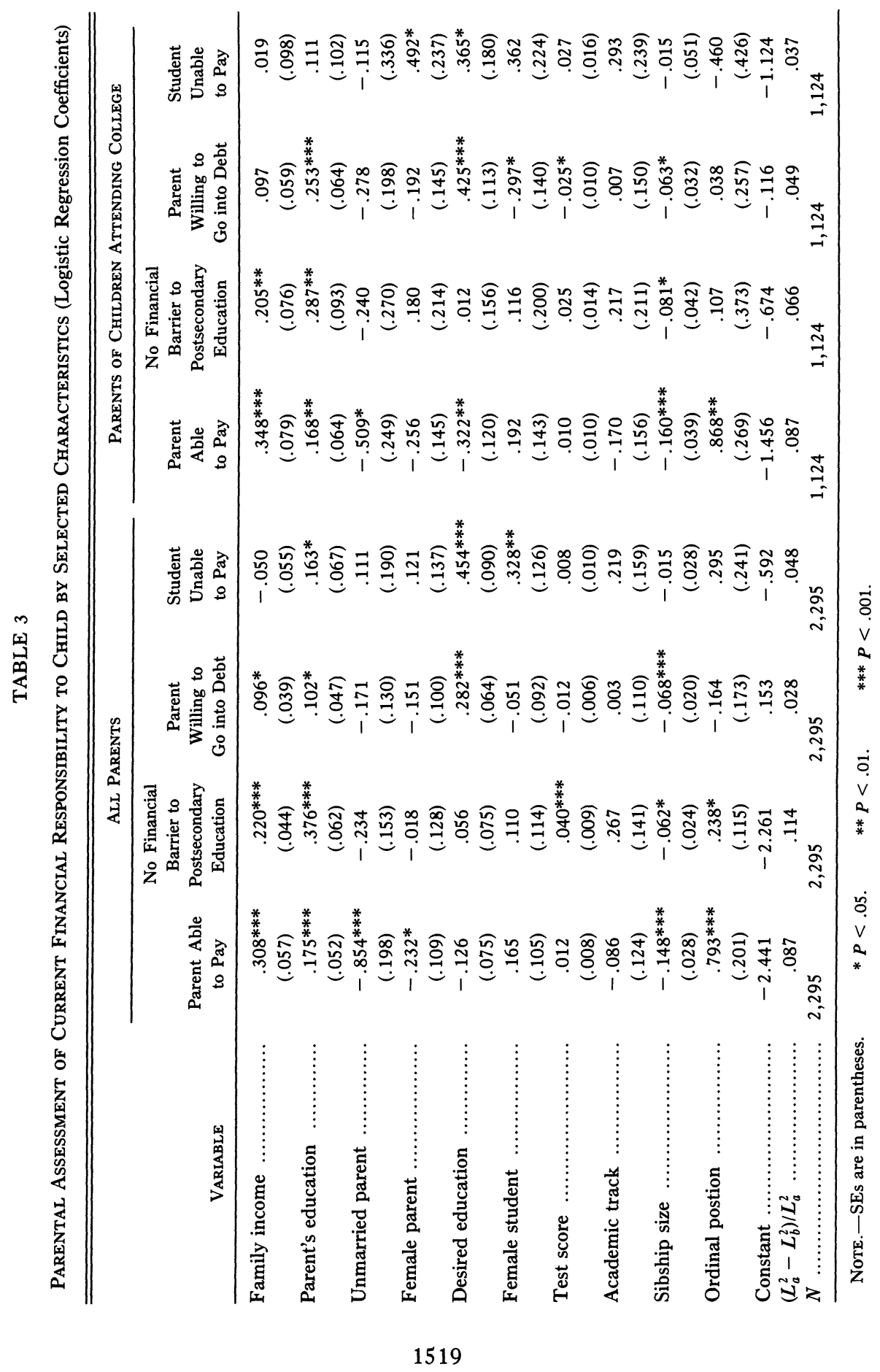


higher education. Perhaps more telling is the parents' willingness to go into debt for their child's education (table 3, col. 3). Resources remain important-parents with more education and income, those who are married, and those with fewer children to share their income are more willing to assume debt. However, although parents find younger children, that is, those of high school age and below, the greater drain on ability to pay and a greater obstacle to financing college (table 3, cols. 1 and 2), parents do not report a greater willingness to go into debt when their younger children reach college age. Educational aspirations influence parental willingness to go into debt, whereas, once again, student traits have mixed effects. For all parents, student characteristics do not influence their willingness to go into debt. However, for those whose child has entered college (col. 7), parents are more willing to assume debt when the child is male and, in contrast to expectations from human capital and status-attainment perspectives, when the child's test scores are low. This counterintuitive pattern may reflect parental willingness to sacrifice for their children when children cannot, by virtue of low test scores or grades, garner scholarship support.

Parental attitudes and the sex of the child play a more prominent role in whether parents believe their child is "able to earn all the money he/ she will need for schooling beyond high school." Parents with more education, with higher educational aspirations for a child, and with daughters see their children as less financially independent (table 3, col. 4). It is interesting that parental perception of the student's ability to pay is the sole dependent variable for the total sample in which the student's sex has any significant direct effect. Except for education, parental resources are only nominally related to this item.

Table 4 analyzes actual parental financial responsibility, specifically, savings accumulated for the child. An examination of savings reveals a concentration of observations at zero dollars. To correct for these floor effects, we employ a Tobit (censored regression) model, which considers not only the likelihood but also the amount of savings (see Tobin [1958], Ameniya [1981], and Maddala [1983] for a detailed discussion of Tobit models). ${ }^{13}$

The Tobit coefficients indicate a strong positive relationship between parental savings and parental education, educational aspirations for chil-

\footnotetext{
${ }^{13}$ In addition to the analyses reported in table 5, we also have used logistic regression and OLS regression to estimate the likelihood and amount of savings, respectively. Unexpectedly, a nontrivial number of parents $(33 \%)$ whose children were not attending college had saved money for their children's education (in contrast to $53 \%$ of parents whose children were enrolled in college). A nearly equal percentage, $29 \%$, of parents who did not aspire for their children to attain a college degree had saved money for their children's education.
} 
TABLE 4

Savings by Selected Characteristics (Tobit Coefficients)

\begin{tabular}{|c|c|c|}
\hline Variable & All Parents & $\begin{array}{l}\text { Parents of Childre } \\
\text { Attending College }\end{array}$ \\
\hline Family income $\ldots \ldots . .$. & $\begin{array}{l}745.11^{* * * *} \\
(156.39)\end{array}$ & $\begin{array}{l}926.50 * * * \\
(214.87)\end{array}$ \\
\hline 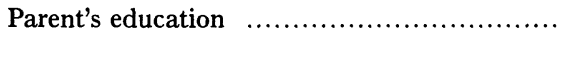 & $\begin{array}{c}1,383.11^{* * * *} \\
(239.67)\end{array}$ & $\begin{array}{c}1,239.10^{* * * *} \\
(204.06)\end{array}$ \\
\hline Unmarried parent ... & $\begin{array}{c}-2,416.30 * * * \\
(534.78)\end{array}$ & $\begin{array}{r}-1,544.70^{*} \\
(713.94)\end{array}$ \\
\hline Female parent $\ldots \ldots \ldots \ldots \ldots \ldots \ldots \ldots \ldots \ldots \ldots \ldots \ldots \ldots \ldots \ldots \ldots \ldots \ldots \ldots$ & $\begin{array}{r}-205.15 \\
(354.77)\end{array}$ & $\begin{array}{c}292.94 \\
(469.95)\end{array}$ \\
\hline Desired education & $\begin{array}{l}984.71 * * * \\
(239.67)\end{array}$ & $\begin{array}{c}139.72 \\
(382.76)\end{array}$ \\
\hline 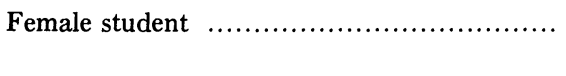 & $\begin{array}{r}-219.45 \\
(334.46)\end{array}$ & $\begin{array}{r}-363.45 \\
(451.60)\end{array}$ \\
\hline Test score $\ldots \ldots \ldots$ & $\begin{array}{c}43.16 \\
(24.80)\end{array}$ & $\begin{array}{l}93.55^{* *} \\
(32.63)\end{array}$ \\
\hline 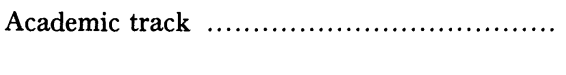 & $\begin{array}{c}792.14^{*} \\
(393.18)\end{array}$ & $\begin{array}{c}778.56 \\
(502.28)\end{array}$ \\
\hline$\ldots \ldots \ldots \ldots \ldots \ldots \ldots \ldots \ldots \ldots+\ldots$ & $\begin{array}{c}-326.98 * * * \\
(81.91)\end{array}$ & $\begin{array}{c}-338.86^{* * *} \\
(111.32)\end{array}$ \\
\hline 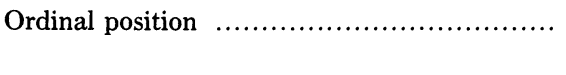 & $\begin{array}{c}2,029.20 * * \\
(633.53)\end{array}$ & $\begin{array}{c}2,472.83^{* *} \\
(845.22)\end{array}$ \\
\hline 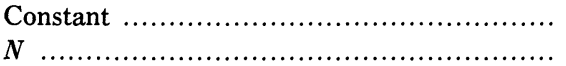 & $\begin{array}{c}-14,285.00 \\
2,295\end{array}$ & $\begin{array}{c}-13,802.70 \\
1,167\end{array}$ \\
\hline
\end{tabular}

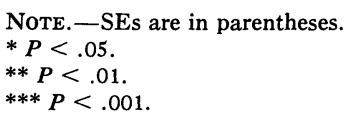

dren, and familial income. Students from single-parent households are especially disadvantaged, as are those with many siblings. Later born students have a distinct financial edge over early borns. Although placement in academic tracking is linked to parental savings, the effect of the student's sex and test scores is slight.

Finally, we ask whether the way that parents funded their own education affects any of the aforementioned endogenous variables. Confining our analysis to parents who advanced beyond a high school education, we test whether perceptions of responsibility and actual saving behavior are altered by whether the parents in fact received financial assistance from their parents. In general, we found support for this prediction. We show in table 5 that, for parents who were financially supported by their parents, the odds of placing financial responsibility on parents instead of students are increased by over $130 \%$ and the odds of emphasizing par- 


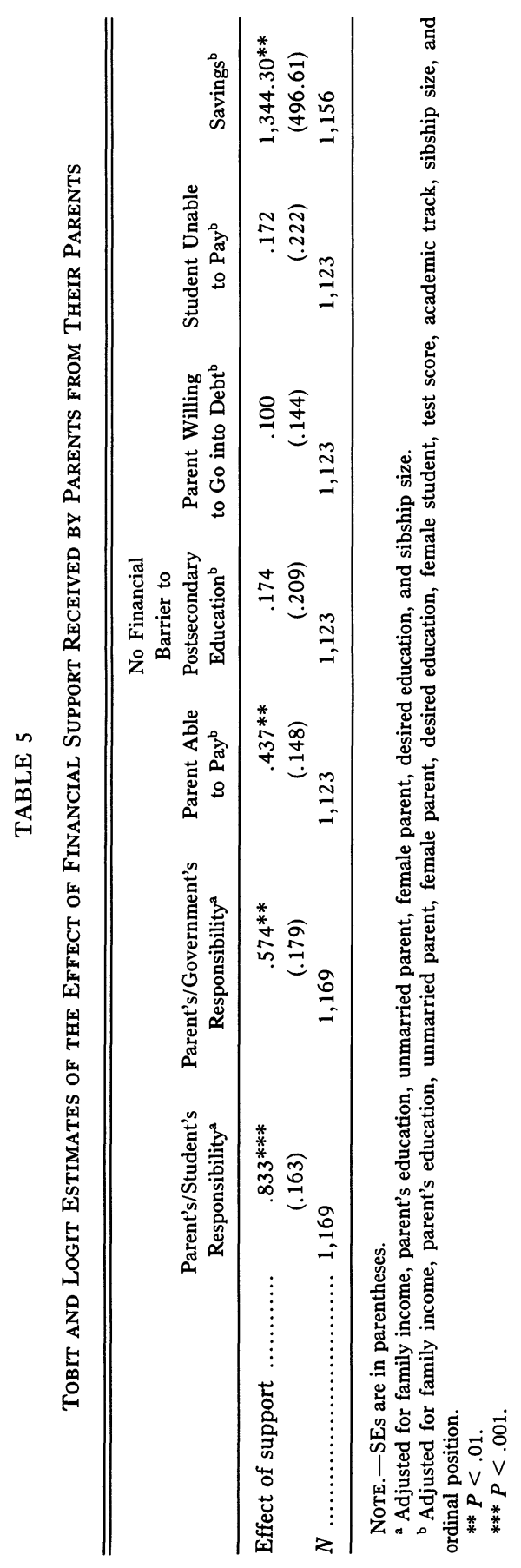


ents' responsibility instead of the government's are increased by $78 \%$. Indeed, the relative influence of this variable on attribution of responsibility is impressive; it is approximately equivalent to the effect of sibship size and exceeds that of every other variable. Similarly, parents who themselves were recipients of parental aid save considerably more for their children. The effects on parental attitudes are not as consistent; only parental views that they can afford to pay for their children's college education is positively linked to whether parents received financial assistance.

\section{DISCUSSION}

The consistent and relatively powerful effects of family income, sibship size, and marital status signify that if the family's structure is conducive to helping children, then parents more readily take on this responsibility. These results are deceptively simple. If, however, one of social science's goals is parsimony in explaining social processes, the simplicity of this reasoning should be welcomed. Nonetheless, this streamlined explanation of parental responsibility may profit from an even more delineated inspection of the familial resource base. Income alone may not provide sufficient information to tap economic assets (Rumberger 1983). In our study, for example, the detrimental effect of marital disruption may result from a diminishment of economic assets beyond that detectable from income. More detailed knowledge of the economic contingencies faced by intact and nonintact families may clarify how variation in parental obligations is expressed.

Four variables deserve special comment: sibship size, ordinal position, whether parents received support for college, and sex. Of equal importance to the pool of available resources (i.e., income) is the number of persons who have to share the resources. Most sociological work, especially status-attainment studies, has merely inserted sibship size as a background factor. Yet it is the most powerful predictor of where parents assign responsibility for financing college. Although not related to parents' perception about their child's being able to earn the money necessary for college, sibship size influences every other attitudinal measure employed as well as the amount of savings amassed. Our results echo the sentiments of the resource-dilution theorists that sibship size has not been given the attention it warrants.

Human capital theory clearly is more attentive than the statusattainment model to the connections between number of children, parental obligations, and status outcomes. However, there may be dissent even among human capital theorists about the causal direction of these 
variables. Indeed, some might ask whether how many children parents have is the consequence of or a covariate of, rather than the precursor to, their propensity to invest in child quality (in this case, savings for college education). Our data obviously cannot offer an answer because we are relying on current parents' views of their obligations. To settle this issue would require retrospective information on attitudes toward parental investment in college at the time parents were having children. We, however, concur with Blake (1989) that the question above ignores a variety of other factors, such as preferences for "parental quality," parental health and fecundity, religion, additional motivations, and efficacy of birth-control usage, which also come into play in the determination of fertility. Moreover, sibship size exerts a significant effect even with the inclusion of educational aspirations and parental background characteristics that, according to Blake, should, at least in part, predict parents' goals for their children and parents' desired family size.

There is an ironic twist to the findings on sibship size. From an industrialization/modernization perspective, modernization coincided with a diminution of familial obligations (Goode 1963). Nevertheless, the declining birth rate, associated with industrialization, that resulted in a decreased family size may have somewhat counteracted this trend. Indeed, parents now can concentrate more heavily on promoting the few children they have. Our conclusions about funding for college illustrate how smaller family size is compatible with greater parental responsibility. Because the human capital model posits that parental investments eventuate in returns from children, a logical extension of our research is to investigate how industrialization, childbearing rates, and sibship size figure into children's obligations to parents. If industrialization has weakened familial ties, then children may feel less obliged to their parents. Moreover, with decreasing family sizes, parents have fewer children to turn to for support. However, according to our results, as the number of children in the family decreases, parental investments, in this case college sponsorship, increase. In turn, children's obligations may intensify in direct proportion to parental investment. Less childbearing also implies that couples, because they are less encumbered with child-rearing duties, are freer to provide for elderly parents. Although variations of and alternatives to these speculations on intergenerational wealth flows and altruism have been made before (Caldwell 1976, 1980; Becker 1981; Willis 1982; Parsons 1984), empirical analysis of these concerns has been scant. Our results and the above propositions underscore the symbiotic relationship between macro-level phenomena and the internal dynamics of the family.

Parents' willingness to go into debt is not directly shaped by ordinal 
position and therefore does not support a preference for their earlier born children or rational calculation of earlier returns on investment. However, parents respond that they are better able to finance the later born child's education by themselves or with outside assistance and have actually saved more for that child's education. At the time later born children reach college age, parental income may be at its peak or parental obligations to other dependents may be receding. Thus it appears that opportunity structure, that is, financial wherewithal rather than preference, more profoundly affects college financing decisions, thereby benefiting later born children. Nonetheless, one should be cautious in interpreting these findings because of our reliance on interfamilial data. A more rigorous test of whether birth order constrains familial resource allocation would be an examination of how parents distribute resources among siblings within families rather than across families.

Resources disseminated to parents in their youth also are important. Our results show how advantages may cut across generations-not simply reflect current familial conditions. Parents whose own parents assisted them are more apt to be financially responsible for their children's education. Perhaps these parents were socialized to accept responsibility, or they are emulating their parents' role models. Social scientists should be attuned to a legacy of familial background effects that transcends the current family context and traces back to previous generations.

What sex the child is does not directly alter parental willingness to go into debt for education or the extent to which parents have set aside funds for college. The absence of a sex effect contrasts with patterns found in Taiwan and Japan. In Taiwan and Japan, sons rather than daughters remain under obligation to parents in terms of repayment, working in family-owned businesses or supporting their parents in old age. In the United States, however, there is either no guarantee of reciprocity by sons or daughters; it is daughters, not sons, who are more likely to provide social support to aging parents (Brody 1981; Kagan 1984; Finley 1989). Because there is no future personal gain in favoring males, parents may be indiscriminate in gender and resource allocation. It is interesting that, even though American parents presumably have lower aspirations for daughters than for sons, this is not reflected in responsibility for college funding.

The sex of the child and of the parent do enter into perceptions of ability to pay for college. Our results suggest sex-specific norms of financial independence. Fathers are more confident than mothers about the family's ability to handle college costs, perhaps exemplifying a tendency for males to deny financial vulnerability (David and Brannon 1976). Parents also express less faith in daughters' than in sons' ability to pay for 
college; however, this appraisal may not be inaccurate given what women can realistically expect to earn in view of sex differences in income.

Our results provide qualified support and hint at future directions for the human capital, status-attainment, and resource-dilution perspectives. The effects of familial assets and the sibship size square with human capital expectations. Indeed, economists may be more cognizant of the importance of these sheerly contextual factors than sociologists. Some other findings, however, undermine the assumption embodied in this theory that parents are rational in their investments in their children. The fact that over one-half of the parents in this survey do not rule out risking financial security on behalf of their children hardly supports the rationality assumption. Moreover, it is implicit in the logic of human capital that more "endowed" children, that is, males and the academically talented, receive a disproportionate amount of parental investment. Curiously, this proposition has not been tested enough empirically, even though it is a major tenet of the human capital argument. Our data do not offer unequivocal support for the endowment effects. The generally weak effects of gender, track placement, and test scores would disappoint staunch advocates of the human capital perspective. As we have demonstrated, in the few models in which gender or ability exerts an effect, there are convenient explanations for these relationships other than from the human capital perspective. Although the norm of rationality may or may not prevail in the commercial sector, it simply may not operate in parent-child interactions. However, our criticism of the rationality assumption is guarded. Given data on how allocation decisions are made among siblings in the same family, we would have a firmer grasp of whether rationality permeates parental distributive decisions.

Critics and even advocates of the status-attainment model contend that continued work in this area has approached redundancy. To the contrary, our results indicate three areas for further explication of the linkage between familial background and educational outcomes. First, the status-attainment model should benefit from a more thorough examination of the role that sibship structure plays in the acquisition of educational credentials. Second, the model's narrow focus on two generations (i.e., parent to child) should be enhanced by studying familial effects on two generations. Third, the model should take a closer look at parental responsibility, especially as related to funding college. Parental assistance intervenes between familial background (and parental aspirations) and children's educational attainment. Moreover, parental support may partly explain exceptions to the general patterns in the status-attainment model. For example, some poor parents may make heroic sacrifices for their children's education, while some wealthy parents may refuse assistance. Knowing the extent of parental help may reconcile cases that do 
not fit the tendency that favors socioeconomically advantaged children in educational advancement. ${ }^{14}$

The strengths of the resource-dilution hypothesis lie in its recognition of the theoretical merit of sibship size and its specification of the mechanisms by which sibship size renders its effect. Yet few studies have directly tested this hypothesis. Our study corroborates the size/dilution principle with respect to economic resources. However, it also raises other issues complicating this seemingly straightforward hypothesis. For example, we need to identify the relative effects of economic, social, and interactional resources during the developing child's life span and to see whether these effects cumulate. We also need to ascertain whether youths deprived of resources suffer irreversible damage and whether there are critical junctures at which children more profoundly require certain types of resources. Moreover, we need to determine whether the resourcedilution hypothesis is supported across historical and cultural contexts.

What predictions about parental support and governmental intervention can we extrapolate from our findings? Overall, our results imply an upswing in parental willingness to invest, given the increasing levels of education of future parents, the predominance of small families, and the large percentage of the next generation of parents currently enjoying parental sponsorship. However, how much the increasing number of disrupted families may undermine parental support is difficult to gauge. Even if the scope of parental support widens, college may represent an unaffordable luxury, should inflationary trends in college costs continue.

Our results provide no indication that the impetus for governmental financial support for college education will increase. In fact, our findings hint that governmental obligations may lessen. Demographic profiles of the United States suggest that the proportion of the population that is immediately concerned about college (i.e., families with college-age youths) will shrink. According to our results, there is hesitancy even among this group to consider the government the primary source of financial support for college. The view that the government should be the main source of assistance is not held even by parents with few resources (i.e., families with low income or large sibship size) whose children's educational prospects look bleak. If this is the general impression, it

\footnotetext{
${ }^{14}$ Coleman (1988) makes a similar observation when discussing parental allocation of social/interactional resources (such as attention) to progeny. He notes that unless the human capital (such as education) enjoyed by the parent is expended on the child, the parent's human capital, no matter how considerable, may prove immaterial to the child's academic growth. He also provides an illustration of the opposite: Asian immigrant parents with low human capital (i.e., few years of formal educational training) who spend an inordinate amount of time doing academic work with their children.
} 
may be difficult to persuade the government to help fund postsecondary education. Without governmental intervention, it would appear that family membership will continue to confer advantages or disadvantages on an individual's college opportunities and therefore on his or her lifetime prospects.

\section{REFERENCES}

Amemiya, Takeshi. 1984. "Tobit Models: A Survey." Journal of Econometrics 24:361.

Anastasi, Anne. 1956. "Intelligence and Family Size." Psychological Reports 53:187203.

Becker, Gary S. 1964. Human Capital. New York: National Bureau of Economic Research.

- 1967. Human Capital and the Personal Distribution of Income. Ann Arbor: University of Michigan Press.

- 1981. A Treatise on the Family. Cambridge, Mass.: Harvard University Press.

Becker, Gary S., and Nigel Tomes. 1976. "Child Endowments and the Quantity and Quality of Children." Journal of Political Economy 84:S143-S162.

Blake, Judith. 1989. Family Size and Achievement. Berkeley and Los Angeles: University of California Press.

Blau, Peter, and Otis Dudley Duncan. 1967. The American Occupational Structure. New York: Wiley.

Blaug, Mark. 1976. "The Empirical Status of Human Capital Theory: A Slightly Jaundiced View." Journal of Economic Literature 14:817-26.

Brinton, Mary C. 1988. "The Social-Institutional Bases of Gender Stratification: Japan as an Illustrative Case." American Journal of Sociology 94:300-334.

Brody, Elaine. 1981. "'Women in the Middle' and the Family Help to Older People." Gerontologist 26:372-81.

Caldwell, John C. 1976. "Toward a Restatement of Demographic Transition Theory." Population and Development Review 2:321-66.

- 1980. "Mass Education as a Determinant of the Timing of Fertility Decline." Population and Development Review 6:225-55.

Carnegie Commission on Higher Education. 1973. Higher Education: Who Pays? Who Benefits? Who Should Pay? New York: McGraw-Hill.

Coleman, James S. 1988. "Social Capital in the Creation of Human Capital." American Journal of Sociology 94:S95-S120.

David, Deborah S., and Robert Brannon. 1976. The Forty-Nine Percent Majority. Reading, Mass.: Addison-Wesley.

Featherman, David L., and Robert M. Hauser. 1978. Opportunity and Change. New York: Academic Press.

Fienberg, Stephen E. 1980. The Analysis of Cross-Classified Categorical Data. Cambridge, Mass.: MIT Press.

Finley, Nancy. 1989. "Theories of Family Labor as Applied to Gender Differences in Caregiving for Elderly Parents." Journal of Marriage and the Family 51:79-86.

Goode, William J. 1963. World Revolution and Family Patterns. New York: Free Press.

$\rightarrow$ Greenhalgh, Susan. 1985. "Sexual Stratification: The Other Side of 'Growth versus Equity' in East Asia." Population and Human Development Review 11:265-314.

Heyns, Barbara, and Thomas L. Hilton. 1982. "The Cognitive Tests for High School and Beyond: An Assessment." Sociology of Education 55:89-102. 
Kagan, Jerome. 1984. The Nature of the Child. New York: Basic.

Lee, Valerie E., and Anthony S. Byrk. 1988. "Curriculum Tracking as Mediating the Social Distribution of High School Achievement." Sociology of Education 61:79-94.

Liebowitz, Arleen. 1974. "Home Investments in Children." Journal of Political Economy 82:111-31.

- 1977. "Parental Inputs and Children's Achievements." Journal of Human Resources 12:242-51.

Maddala, G. S. 1983. Limited-Dependent and Qualitative Variables in Econometrics. Cambridge: Cambridge University Press.

Manski, C. F. 1980. "Structural Models for Discrete Data: The Analysis of Discrete Choice." Research Report no. 130. Hebrew University of Jerusalem, Department of Economics.

Miller, Scott. 1985. "College Costs: How Do Families Pay?” Educational Record 63:40-43.

Olson, Lorayn, and Rachel Rosenfeld. 1984. "Parents and the Process of Gaining Access to Student Financial Aid." Journal of Higher Education 55:455-80.

Parsons, Donald O. 1984. "On the Economics of Intergenerational Control." Population and Development Review 10:41-54.

Preston, Samuel H. 1976. "Family Sizes of Children and Family Sizes of Women." Demography 32:105-14.

Rumberger, Russell W. 1983. "The Influence of Family Background on Education, Earnings, and Wealth." Social Forces 61:755-73.

Sewell, William H., and Robert M. Hauser. 1976. "Causes and Consequences of Higher Education: Models of the Status Attainment Process." Pp. 9-28 in Schooling and Achievement in American Society, by William H. Sewell, Robert M. Hauser, and David L. Featherman. New York: Academic Press.

Steelman, Lala Carr, and Brian Powell. 1989. "Acquiring Capital for College: The Constraints of Family Configuration." American Sociological Review 54:844-55.

Taubman, Paul, and Jere R. Behrman. 1986. "Effect of Number and Position of Siblings on Child and Adult Outcomes." Social Biology 33:22-33.

Tobin, James. 1958. "Estimation of Relationship for Limited Dependent Variables." Econometrics 26:24-36.

Vanneman, Reeve, and Fred Pampel. 1977. "The American Perception of Class and Status." American Sociological Review 42:422-37.

Willis, Robert R. 1982. "The Direction of Intergenerational Transfer and Demographic Transition: The Caldwell Hypothesis Reexamined." Population and Development Review ("Income Distribution and the Family," edited by Yoram BenPorath) 8:S207-S234. 